\title{
Functionalised zinc oxide nanotube arrays as electrochemical sensors for the selective determination of glucose
}

\author{
Syed Usman Ali, M Kashif, Zafar Hussain Ibupoto, M Fakhar-e-Alam, \\ U Hashim and Magnus Willander
}

\section{Linköping University Post Print}

N.B.: When citing this work, cite the original article.

This paper is a postprint of a paper submitted to and accepted for publication in Micro \& Nano Letters and is subject to Institution of Engineering and Technology Copyright. The copy of record is available at IET Digital Library:

Syed Usman Ali, M Kashif, Zafar Hussain Ibupoto, M Fakhar-e-Alam, U Hashim and Magnus Willander, Functionalised zinc oxide nanotube arrays as electrochemical sensors for the selective determination of glucose, 2011, Micro \& Nano Letters, (6), 8, 609-613. http://dx.doi.org/10.1049/mnl.2011.0310

Copyright: Institution of Engineering and Technology (IET) http://www.theiet.org/

Postprint available at: Linköping University Electronic Press http://urn.kb.se/resolve?urn=urn:nbn:se:liu:diva-70754 


\title{
Functionalized $\mathrm{ZnO}$ nanotubes arrays as electrochemical sensor for the selective determination of glucose
}

\author{
Syed M. Usman Ali *, 1,2, M. Kashif ${ }^{3}$, Zafar Hussain Ibupoto ${ }^{1}$, M. Fakhar-e- Alam ${ }^{1}$, \\ U. Hashim $^{3}$, Magnus Willander ${ }^{1}$, \\ ${ }^{1}$ Physical Electronics and Nanotechnology Division, Department of Science and Technology, \\ Campus Norrköping, Linköping University, SE-60174 Norrköping, Sweden. \\ ${ }^{2}$ Department of Electronic Engineering, NED University of Engineering and Technology, \\ Karachi-75270, Pakistan. \\ ${ }^{3}$ Nano Biochip Research Group, Institute of Nano Electronic Engineering (INEE), University \\ Malaysia Perlis (UniMAP), 01000 Kangar, Perlis, Malaysia.
}

\begin{abstract}
In the present work, highly oriented single-crystal zinc oxide nanotubes (ZnO-NTs) arrays were prepared by a trimming of $\mathrm{ZnO}$ nanorods along the c-axis on the gold coated glass substrate having the diameter of 100-200 nm and a length of $\sim 1 \mu \mathrm{m}$ using low temperature aqueous chemical growth process. The prepared (ZnO-NTs) arrays were further used as an electrochemical enzyme-based glucose sensor through immobilizing of glucose oxidase (GOD) by physical adsorption method in conjunction with a Nafion coating. The electrochemical response of sensor found to be linear over a relatively wide logarithmic concentration range from $0.5 \times 10^{-6} \mathrm{M}$ to $12 \times 10^{-3} \mathrm{M}$. The proposed sensor showed a high sensitivity of $69.12 \mathrm{mV} /$ decade with $\mathrm{R}=0.9934$ for sensing of glucose. A fast response time less than $4 \mathrm{~s}$ with good selectivity, reproducibility and negligible response to common interferents such as ascorbic acid and uric acid was prevailed.
\end{abstract}

Index Terms: $\mathrm{ZnO}$ nanotubes (ZnO-NTs), electrochemical nanodevices, potentiometric nanosensor, glucose oxidase (GOD) and Nafion ${ }^{\circledR}$ membrane

*Corresponding author.

Email address: 1. syeal@itn.liu.se 


\section{Introduction}

Glucose biosensors are by far the most widely studied type of biosensors and numerous designs have been proposed. However, converting the biological signal to an easily processed electronic signal is challenging due to the complexity of connecting an electronic device directly to a biological environment. Electrochemical biosensors provide an attractive means to analyze the content of a biological sample due to the direct conversion of a biological event to an electric signal. Over the past decades, several sensing concepts and related devices have been developed. The inherent advantages of electrochemical biosensors are their robustness, easy miniaturization, excellent detection limits, also with small analyte volumes, and ability to be used in turbid biofluids with optically absorbing and fluorescing compounds $[1,2]$. Among these biosensors, most glucose biosensors are on amperometric principles due to good sensitivity and low detection limit. However, upon applying a high polarizing voltage (Vapp. $=0.6-0.8 \mathrm{~V}$ ) interfering substances such as ascorbic acid and uric acid, which are commonly present in biological fluids are also oxidized, leading to nonspecific signals [3]. Several artificial redox mediators have been investigated as electron acceptors to solve these problems [4-13]. Additionally, the sensor electrodes have been modified to enhance the performance of amperometric glucose biosensors [14-18]. The interferences mentioned above are avoided in thermometric biosensors such as enzyme thermistor [19]. In addition their excellent stability makes them particularly suitable for long term monitoring. Compared to amperometric biosensors, since no extra potential is required, potentiometric biosensors have an advantage in selectivity and simplicity. However, a limitation of ion sensitive electrodes (ISEs) is that only charged molecules can be directly detected. This obstacle can be overcome by letting the analyte undergo a reaction, such as an enzyme reaction, that produces a detectable ion in an amount proportional to the concentration of the analyte in the sample. In the enzyme field effect transistor (En-FET), this is taken a step further by combining the enzyme reaction with 
an ion sensitive field effect transistor (ISFET) was first introduced by Caras and Janata [20]. Many potentiometric devices are based on various forms of FET devices to measure $\mathrm{pH}$ changes, selective ion concentrations, and the kinetics of biocatalytic reactions involving enzymes [21]. The conversion of a FET into a sensing device normally involves the replacement of the metal gate electrode by a biochemically sensitive surface like an analyte selective membrane, an enzyme layer or an ion-conductive solution, etc., which is brought into contact with the analyte solution [22]. Also present in the analyte solution is a reference electrode, which completes the circuit via the gate voltage bias [23, 24].

The use of nanomaterials has allowed the introduction of many new signal transduction technologies in biosensors resulting in improved sensitivity and performance. Because of their sub-micrometer dimensions, nanosensors, nano probes, and other nano-systems have allowed simple and rapid analyses in vivo. Their implementation as highly sensitive electrodes is one obvious example, such as the platinum electrode network proposed by Wang et al. for glucose detection [25]. Among the nanostructures, zinc oxide $(\mathrm{ZnO})$ is of special interest to biological sensing due to many favorable properties. $\mathrm{ZnO}$ is a distinguished material with some special properties due to the wide direct band gap $(3.37 \mathrm{eV})$ and large exciton binding energy (60 meV). Recently, extensive research efforts have been focused on the synthesis, characterization and device application of $\mathrm{ZnO}$ nano and micro-materials. One-dimensional (1D) $\mathrm{ZnO}$ nanostructures can have significant applications in optics, optoelectronics, sensors, and actuators due to their remarkable semiconducting and piezoelectric properties [26-30]. The $\mathrm{ZnO}$ nanomaterials can be used in a variety of electrochemical bio-sensing schemes due to their unique advantages in combination with immobilized enzymes. Due to such unique properties, these $\mathrm{ZnO}$ nanosensors offer some significant advantages owing to their small size and high surface area to volume ratios allowing larger signals, better catalysis and the more rapid movement of analyte through sensors show higher sensitivity and a lower limit of 
detection (LOD) as compared to those prepared from bulk $\mathrm{ZnO}$ devices. As compared to $\mathrm{ZnO}$ nanorods and nanowires, $\mathrm{ZnO}$ nanotube ( $\mathrm{ZnO}-\mathrm{NTs})$ structures possess lots of interesting unique properties such as porous structures and large surface areas and there have been reports on the use of $\mathrm{ZnO}$ tubular structures as sensors with improved performance and higher sensitivity compared to $\mathrm{ZnO}$ nanorods and nanowires [31-34]. In general, nanostructures such as $\mathrm{ZnO}$ nanowires, nanotubes and nonporous are attractive for their versatile roles in bioelectronics and nanoelectronics applications and they are increasingly being used as building blocks for biosensing purposes. Due to the remarkable properties like non-toxicity, bio-safety, excellent biological compatibility, high-electron transfer rates, enhanced analytical performance, increased sensitivity, easy fabrication and low cost. Moreover, $\mathrm{ZnO}$ has a high isoelectric point (IEP) of about 9.5 , which should provide a positively charged substrate for immobilization of low IEP proteins or enzyme such as glucose oxidase (IEP $\approx 4.5$ ) as described in our earlier investigations [35-38]. In addition, $\mathrm{ZnO}$ has high ionic bonding $(60 \%)$, and it's dissolve very slowly at biological $\mathrm{pH}$ values.

In this study, we have successfully demonstrated the determination of glucose with improved electrochemical response by using the $\mathrm{ZnO}-\mathrm{NT}$ s arrays based biosensor fabricated by a two-step aqueous chemical growth (ACG) method. This method is advantageous by being a low cost, simple with high yield, low temperature deposition process and also proves to be less hazardous compared to other methods. The enhanced electrochemical response of the $\mathrm{ZnO}-\mathrm{NTs}$ arrays based sensor as compared to our earlier investigation with $\mathrm{ZnO}$ nanowires [28] can be attributed to the unique properties of our sensor electrode like the vast surface to volume ratio due to the porous structure of $\mathrm{ZnO}-\mathrm{NT}$ s arrays which can provide a favourable microenvironment for the immobilization of enzyme GOD, the enzyme catalysis of the glucose oxidation on electrode and excellent electrical contact between the gold electrode and the ZnO-NTs. In addition, due to the large surface to volume ratio of the porous 
structures of the $\mathrm{ZnO}-\mathrm{NTs}$, the sensor electrode enhances the sensitivity for analytes as demonstrated by the detection of glucose without the presence of a mediator.

\section{Experimental detail}

\subsection{Materials}

Glucose oxidase (E.C. 1.1.3.4) from Aspergillus niger 360 U/mg (BBI Enzymes (UK) Ltd.). Bovine serum albumin (BAS $\geq 98 \%$ ), glutaraldehyde (50\% solution), Nafion (5 wt.\%), d-(+)glucose $(99.5 \%)$, potassium chloride, zinc nitrate hexahydrate and hexamethylenetetramine (HMT) were purchased from Sigma-Aldrich. Phosphate buffered, $10 \mathrm{mM}$ solution (PBS) was prepared from $\mathrm{Na}_{2} \mathrm{HPO}_{4}$ and $\mathrm{KH}_{2} \mathrm{PO}_{4}$ (Sigma-Aldrich) with sodium chloride in $0.135 \mathrm{mM}$, the $\mathrm{pH}$ was adjusted to 7.4. Glucose stock solution was kept at least $24 \mathrm{~h}$ after preparation for mutarotion. All chemicals used (Sigma, Aldrich) were of analytical reagent grade.

\subsection{Fabrication of (ZnO-NTs) arrays on gold coated glass}

To prepare the ZnO-NTs arrays based sensor electrodes, the glass was used as a substrate and cleaned with acetone, isopropanol and de-ionized water .After cleaning, a titanium (Ti) thin film with $20 \mathrm{~nm}$ thicknesses was evaporated as an adhesive layer then a gold (Au) thin film with $100 \mathrm{~nm}$ thickness was evaporated on a glass substrate as a gold electrode. To obtain the well-aligned hexagonal ZnO-NTs arrays on the prepared electrode surface, we followed the low temperature ACG method described in [39-41]. In the ACG method, prepared substrates were spin coated with seed solution and annealed at $200{ }^{\circ} \mathrm{C}$ for 20 minutes and zinc nitride hexahydrate $\left[\left(\mathrm{Zn}\left(\mathrm{NO}^{3}\right)_{2} 6 \mathrm{H}_{2} \mathrm{O}\right)\right]$ was mixed with hexamethylenetetramine $\left[\mathrm{C}_{6} \mathrm{H}_{12} \mathrm{~N}_{4}\right]$ using the same molar concentration of $0.05 \mathrm{M}$ for both solutions. Then, the substrates were placed in the prepared solutions using Teflon sample holders and kept in an oven preheated up to at $90^{\circ} \mathrm{C}$ for 4-6 hours. During the $\mathrm{ZnO}$ nanorods growth process, a small part of the gold coated glass substrates were covered and used as a contact area. After the growth was completed, the 
grown nanorods arrays were cleaned in de-ionized water and dried at room temperature. In the second step, the fabrication of ZnO-NTs arrays was carried out as described [42] by suspending the prepared sample with the $\mathrm{ZnO}$ nanorods upside down in $100 \mathrm{ml}$ aqueous solution of potassium chloride $(\mathrm{KCl})$. The experiment was repeated several times while varying growth parameters like temperature ( the temperature of the solution was kept at 85 ${ }^{\circ} \mathrm{C}$ ), concentration of precursor $(\mathrm{KCl})$ from $0.2 \mathrm{M}$ to $4.5 \mathrm{M}$ as well as etching time from 3 to $15 \mathrm{hrs}$. For obtaining desired etching and fine structure control of the ZnO-NTs arrays, these variables must all be optimized. After performing carefully chemical etching of $\mathrm{ZnO}$ nanorods along the c-axis direction, we finally obtained the ZnO-NTs arrays with 100 to $200 \mathrm{~nm}$ in diameter and $\sim 1.3 \mu \mathrm{m}$ in length. The SEM image and the schematic diagram of the obtained ZnO-NTs arrays are shown in figure $1(a-b)$.

\subsection{Enzyme (GOD) immobilization on ZnO-NTs arrays}

To investigate the electrochemical response of the ZnO-NTs arrays, we prepared six $(n=6)$ sensor electrodes for the experiments. Glucose oxidase (GOD) solution, prepared by using glucose oxidase (E.C. 1.1.3.4) from Aspergillus niger by dissolving $10 \mathrm{mg} / \mathrm{ml}$ GOD in PBS at $\mathrm{pH}$ 7.4. Before the immobilization of enzymes (GOD) on the surface of the sensor electrode, the sensor electrode was rinsed with PBS to generate a hydrophilic surface. To immobilize the enzymes (GOD) on the tailored $\mathrm{ZnO}-\mathrm{NT}$ s arrays on gold coated electrode, $5 \mu \mathrm{l}$ of prepared GOD solution was deposited and left in air for $2 \mathrm{~h}$ to dry. The cross-linking procedure was carried out by adding $2 \mu \mathrm{l}$ aqueous solution containing $2.5 \%$ glutaraldehyde and $0.5 \%$ Nafion onto the electrodes surface. After drying at room temperature, $2 \mu 1$ of $0.5 \%$ Nafion solution was further applied onto the electrodes surface to prevent possible enzyme leakage and eliminate foreign interferences. The immobilized $\mathrm{ZnO}-\mathrm{NTs}$ arrays are shown in figure 1(c). All enzyme electrodes were stored in dry condition at $4{ }^{0} \mathrm{C}$ when not in use. After completing these steps, the sensors were initially checked potentiometrically in $100 \mu \mathrm{l}$ of $0.5 \mu \mathrm{M}$ glucose 
solutions with an $\mathrm{Ag} / \mathrm{AgCl}$ reference electrode purchased from Metrohm (3MKCl). A pH meter (Model 215, Denver Instrument) was used to measure the potentiometric output voltage of the sensors presented here. For the time response measurements, a model 363A potentiostat/galvanostat (EG \& G, USA) was used.

\section{Results and discussion}

\subsection{Electrochemical measurements with ZnO-NTs sensors}

The electrochemical cell voltage (electromotive force) changed when the composition of the test electrolyte was altered. These changes can be related to the concentration of ions in the test electrolyte via a calibration procedure. The electrochemical potential cell can be described by following representation:

$$
\mathrm{ZnO} \text { s }\left|\mathrm{Zn}^{+2} \mathrm{PBS}_{\text {sol }}\right| \mid \mathrm{Ag} / \mathrm{AgCl} \text { PBS sol } \mid \mathrm{Ag}
$$

The electrochemical response of the $\mathrm{ZnO}-\mathrm{NTs}$ arrays sensor versus an $\mathrm{Ag} / \mathrm{AgCl}$ reference electrode was measured at room temperature $(23 \pm 2){ }^{0} \mathrm{C}$. The sensor as fabricated is sensitive to the concentration changes of glucose in PBS. The measurements started after conditioning the sensor electrode in PBS buffer at $\mathrm{pH} 7.4$ for $30 \mathrm{~min}$ and when the electrodes were inside the PBS, a constant potential was observed. When freshly prepared $0.5 \mu \mathrm{M}$ glucose solution was tested then a change in a signal was observed. The response of the electrochemical potential difference of the $\mathrm{ZnO}$ nanotubes based sensor to the changes in buffer electrolyte glucose was measured for the range of $0.5 \mu \mathrm{M}$ to $12 \mathrm{mM}$ and shows that this glucose dependence is linear and has sensitivity equal to $69.12 \mathrm{mV} /$ decade at around $23 \circ \mathrm{C}$ (Fig. 2a). This linear dependence implies that such sensor configuration can provide a large dynamic range. Avery fast response time was noted over the whole concentration range with $95 \%$ of the steady state voltage achieved within $4 \mathrm{~s}$ as shown in figure 2(b). The tested sensor configuration showed large dynamic ranges with an output response (EMF) that was linear vs. the logarithmic concentration of glucose going from $15 \mathrm{mV}$ for $0.5 \mu \mathrm{M}$ and $315 \mathrm{mV}$ for $12 \mathrm{~m}$ 
M glucose. This corresponds to slopes of around $69.12 \mathrm{mV} /$ decade with a regression coefficient $\mathrm{R}=99.34$ as shown in figure 2 (a). An electrochemical response from ZnO-NTs arrays sensor in the $100 \mu \mathrm{M}$ glucose solution was observed around $160 \mathrm{mV}$. The response stayed around $160 \mathrm{mV}$ regardless of the analyte solution volume. During all experiments the ZnO-NTs arrays sensor followed the Nernst's expression:

$$
E=E_{0}-0.05916 \mathrm{~V} / \mathrm{n} \log [\text { Reduced] / [Oxidized] }
$$

It is very important to note that $\mathrm{ZnO}-\mathrm{NT}$ s arrays are relatively stable around a neutral $\mathrm{pH} 7.4$ and this gives these sensors much more bio-compatibility in biological fluids and species since most of the biological fluids is around $\mathrm{pH}$ of 7.4. The sensing mechanism of most electrochemical glucose sensors is based on an enzymatic reaction catalyzed by glucose oxidase (GOD) as schematically illustrated in the experimental setup shown in figure 3 . The figure 3 describes the sensing mechanism of the glucose using immobilized GOD enzymes on $\mathrm{ZnO}-\mathrm{NTs}$ arrays sensor electrode, as a result of this reaction; $\delta$-gluconolactone and hydrogen peroxide are produced. These two products and the oxygen consumption can be used for the glucose determination. With the $\mathrm{H}_{2} \mathrm{O}$ availability in the reaction, gluconolactone is spontaneously converted to gluconic acid, which at neutral $\mathrm{pH}$, form the charged products of gluconate - and proton $\left(\mathrm{H}^{+}\right)$, according to the equations (1) and (2) given below:

$$
\mathrm{H}_{2} \mathrm{O}+\mathrm{O}_{2}+\beta \text {-D-glucose } \underset{\mathrm{GOD}}{\longrightarrow} \delta \text {-gluconolactone }+\mathrm{H}_{2} \mathrm{O}_{2}
$$

$\delta$-gluconolactone spontaneous $\quad$ gluconate ${ }^{-}+\mathrm{H}^{+}$ 


\subsection{Reproducibility and influence of temperature}

The reproducibility and long term stability was evaluated by using 6 different ZnO-NTs arrays sensor electrodes constructed independently; the sensor to sensor reproducibility in 1 $\mathrm{mM}$ glucose solution was tested during periodic measurements after being kept in refrigerator at $4^{\circ} \mathrm{C}$ for three weeks. The sensors retained around $90 \%$ of its original response with good reproducibility and repeatability in pH 7.4 PBS solution as shown in figure 4 (a). The influence of the varying temperature on the ZnO-NTs arrays sensor response was also examined between $20^{\circ} \mathrm{C}$ and $75^{\circ} \mathrm{C}$. As shown in figure 4(b), the EMF response gradually increases with the increasing of temperature and reaches to its maximum value at around 50 ${ }^{\circ} \mathrm{C}$. This is because each enzyme has maximum activity at optimum temperature condition. After $50{ }^{\circ} \mathrm{C}$, the response decreases which is caused by the natural thermal degradation of the enzymes. Although the $\mathrm{ZnO}-\mathrm{NTs}$ arrays sensor shows a maximum response at $50{ }^{\circ} \mathrm{C}$. Room temperature $(23 \pm 2){ }^{\circ} \mathrm{C}$ is still chosen for this work in order to prevent possible solution evaporation at higher temperature and ease of operation.

\subsection{Study of interferences and stability}

The selectivity of a glucose sensor depends on two major factors that are the enzyme-analyte reaction and selective measurements. The enzyme-analyte reaction is very specific due to the nature of the enzyme (GOD) functionality. The GOD reaction with $\beta$-D-glucose is highly specific without any major interfering reaction with other types of sugars. It could however, be useful to check possible interferences from reducing agents such as ascor bic acid and uric acid, which are well known interferents with amperometric glucose measurements methods. As clearly seen from the output response of the sensor, the addition of these potential interferents does not substantially change the signal. Addition of $100 \mu \mathrm{M}$ of ascorbic acid or uric acid to $1 \mathrm{mM}$ glucose only generated some extra noise as shown in Fig. 5. We suggest that the good selectivity of the present biosensor can be attributed to the permselective 
(charge-exclusion) property [43-44] of Nafion films coated on the electrode. The proposed ZnO-nanotubes based sensor demonstrated an excellent response to the glucose. Therefore, based on our obtained results during the experiments, we proposed instead of fabricating the $\mathrm{ZnO}$ nanorods/nanowires/nanotubes on the gate area inside the transistor (e.g., on the MOSFET/AlGaN/GaN HEMT devices), $\mathrm{ZnO}$ nanorods/nanowires/nanotubes can be interfaced/integrated as an extended gate $[36,45]$. In this way, the chemically sensitive gate is then separated from the rest of the transistor construction, and the sensing area increases significantly as compared to gate areas of some published sensors based on transistors, e.g., HEMT [46]. Thereby, the biosensor construction is much facilitated as the enzyme can be readily immobilized on the nanomaterials, and applied in a variety of different sensors or flow systems designs without problems arising from, e.g., encapsulation of the electronics etc.

\section{Conclusion}

In conclusion, we have successfully demonstrated a glucose biosensor using immobilized zinc oxide nanotubes (ZnO-NTs) arrays. Our experimental results showed that the proposed sensor electrode have a sensitivity as high as around twice that of determined by zinc oxide nanowires reported in elsewhere in the literature. This can be ascribed to the fact that small dimensional $\mathrm{ZnO}-\mathrm{NTs}$ arrays have a higher surface area, subsurface oxygen vacancies and provide a larger effective surface area with higher surface-to-volume ratio as compared to zinc oxide nanowires arrays thus enables the sensor with a higher sensitivity. The good performance in improved sensitivity, stability, selectivity, reproducibility, negligible interference and rapid response (EMF) by our proposed sensor also makes it suitable for externally integrating/interfacing nano-sensing element to commercial (low threshold) FET devices giving the advantages of simplicity and low cost for the enzymatic detection of biochemically important substances. All these advantageous features can make the proposed 
biosensor applicable in wireless physiological parameters monitoring, environmental, food or other areas. 


\section{Figure Captions}

Fig. 1: (a) Schematic diagram of ZnO-NTs arrays sensors (b) A typical scanning electron microscopy (SEM) image of ZnO-NTs arrays grown on gold coated glass using low temperature chemical growth. The figure shows that the diameter of the ZnO-NTs arrays is in the range of 100-200 $\mathrm{nm}$ (c) the immobilized ZnO-NTs arrays with inset SEM image is showing the magnifying image of ZnO-NTs arrays and (d) SEM image of ZnO-NTs after measurements.

Fig. 2: (a) Time response of the sensor electrodes in $500 \mu \mathrm{M}$ glucose solution (b) Calibration curve of the ZnO-NTs arrays sensor electrode reveals the linear relationship between the of output response (EMF) and glucose concentrations with $\mathrm{Ag} / \mathrm{AgCl}$ reference electrode.

Fig. 3: Schematic diagram showing the measuring setup and sensing mechanism of the glucose

Fig. 4: (a) the sensor to sensor reproducibility of six ( $\mathrm{n}=6) \quad \mathrm{ZnO}-\mathrm{NTS}$ arrays sensor electrodes in $500 \mu \mathrm{M}$ glucose solution (b) EMF response with the influence of varying temperature.

Fig. 5: Calibration curve showing the study of interferences with time trace line of output response (EMF) change with time after adding $100 \mu \mathrm{M}$ ascorbic acid (AA ) and uric acid (UA) in $1 \mathrm{mM}$ glucose solution. 
Figure 1

(a)
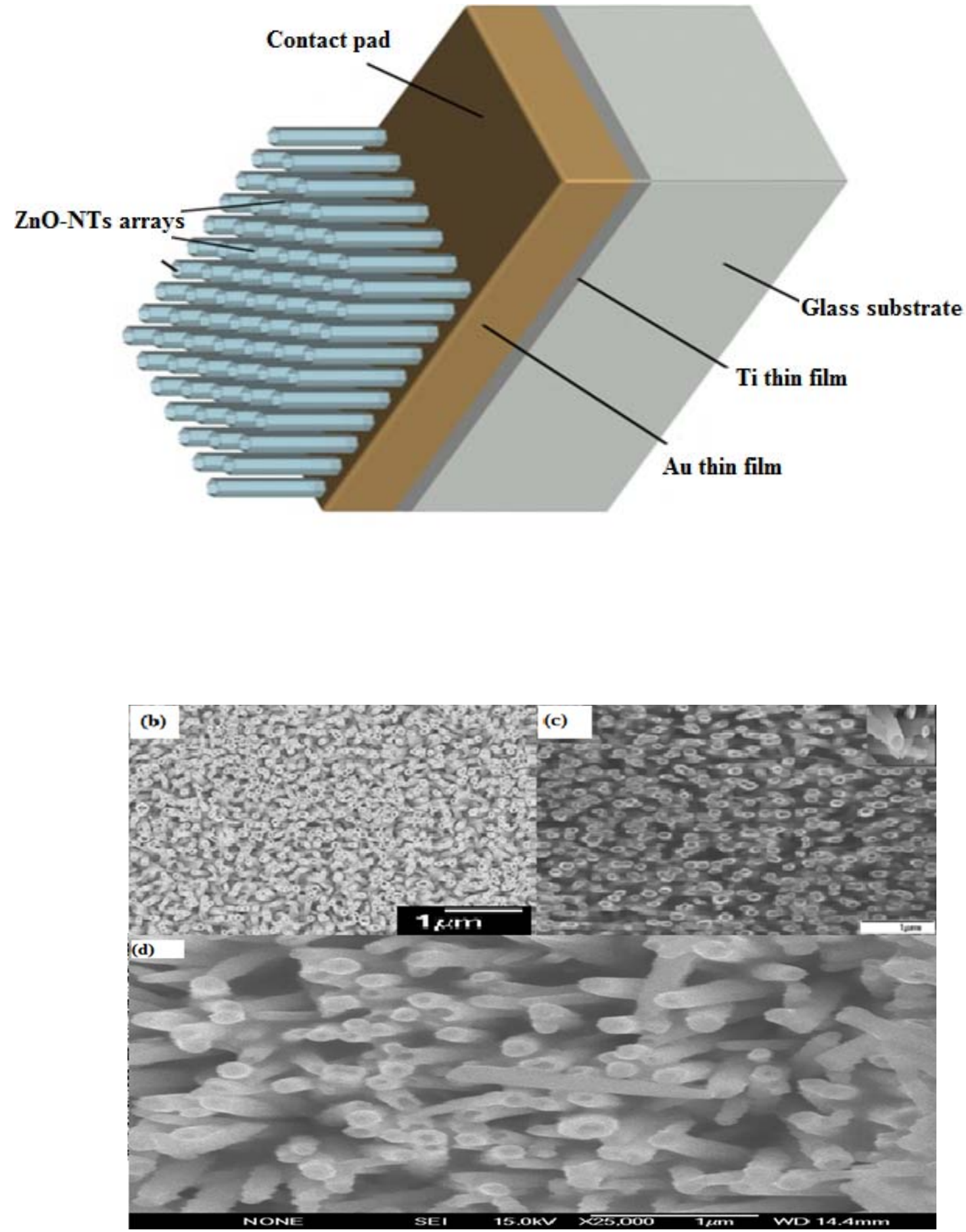
Figure 2

(a)

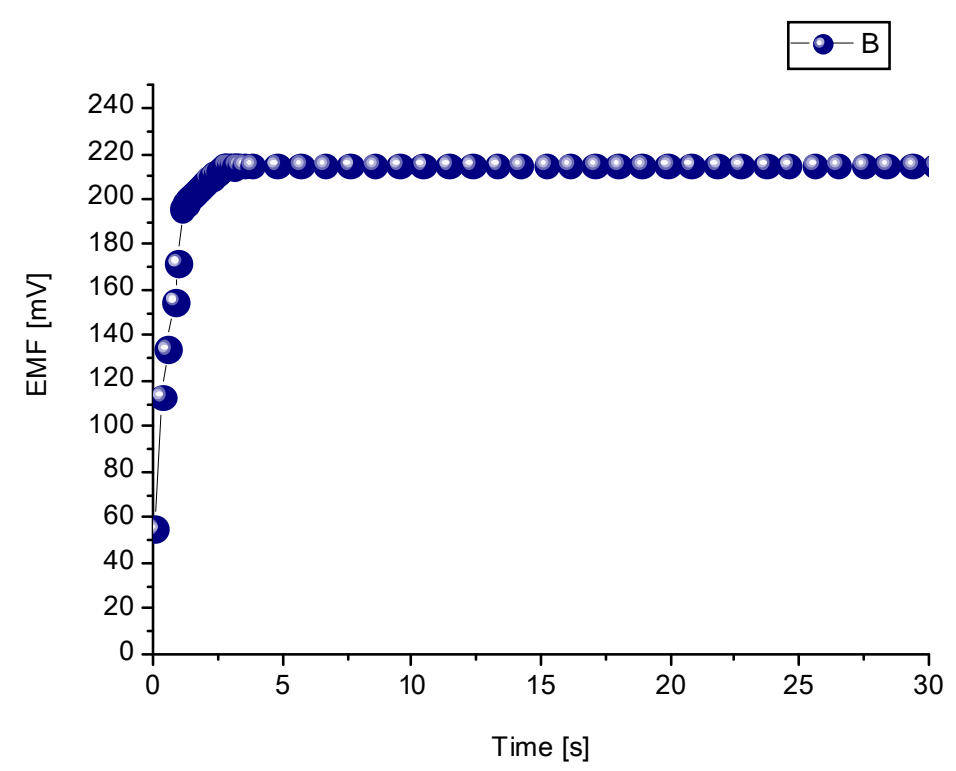

(b)

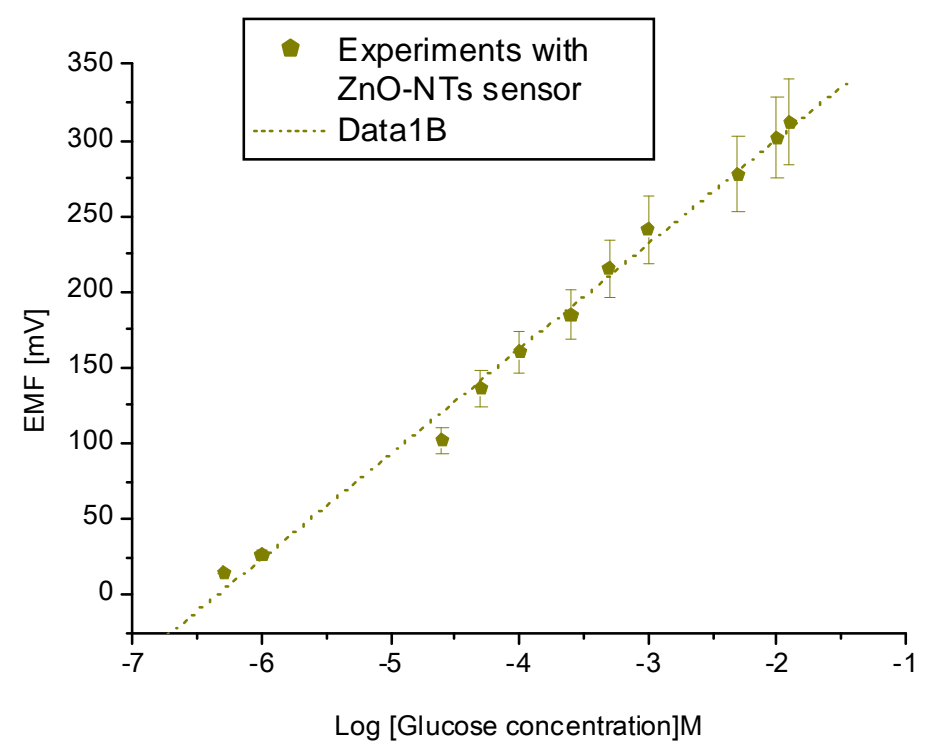


Figure 3

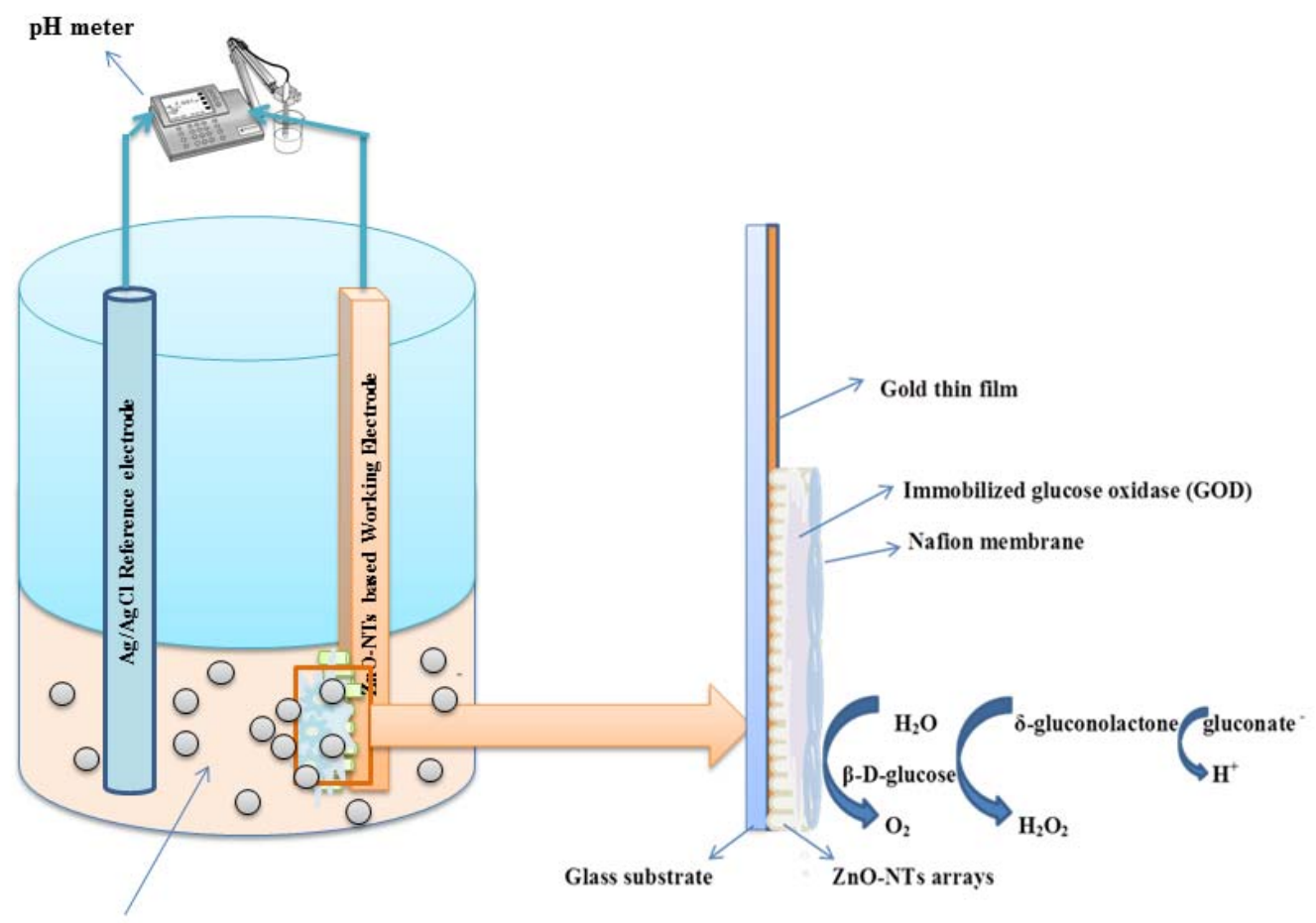

Glucose solution 
Figure 4

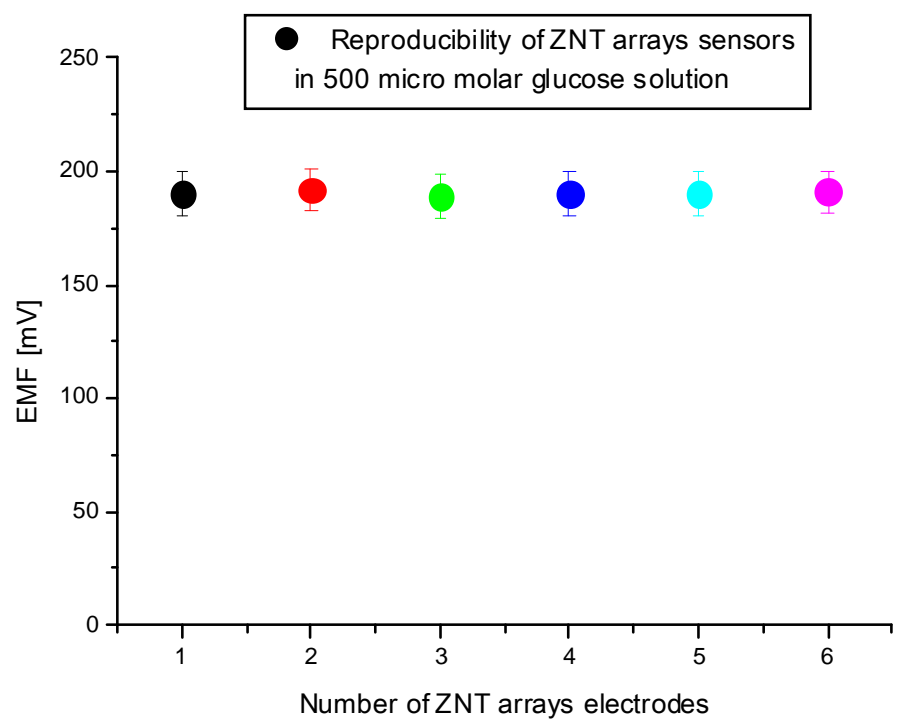

(b)

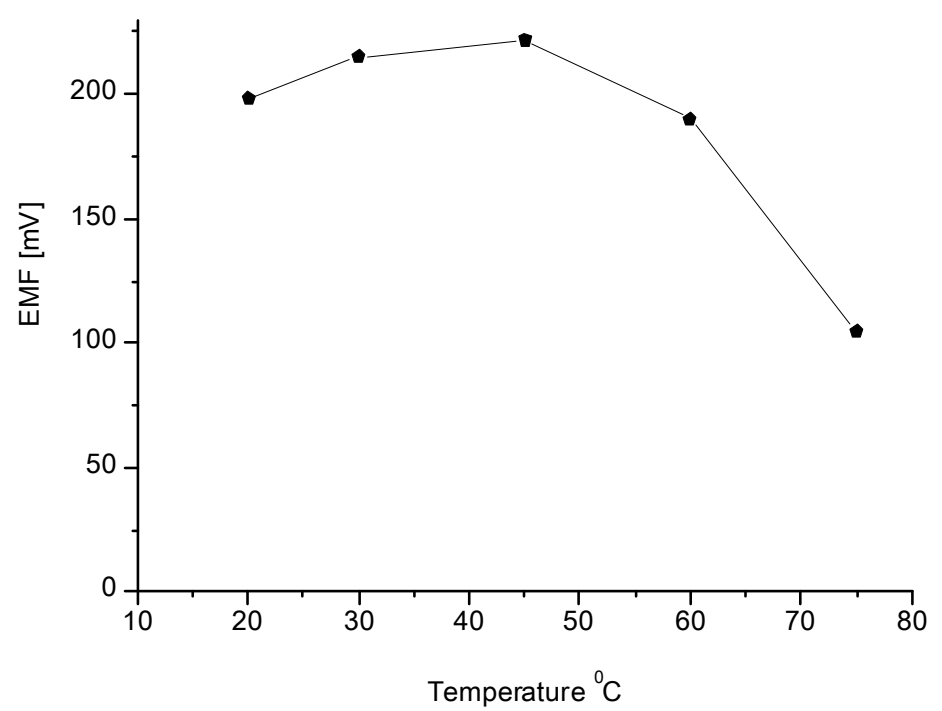


Figure 5

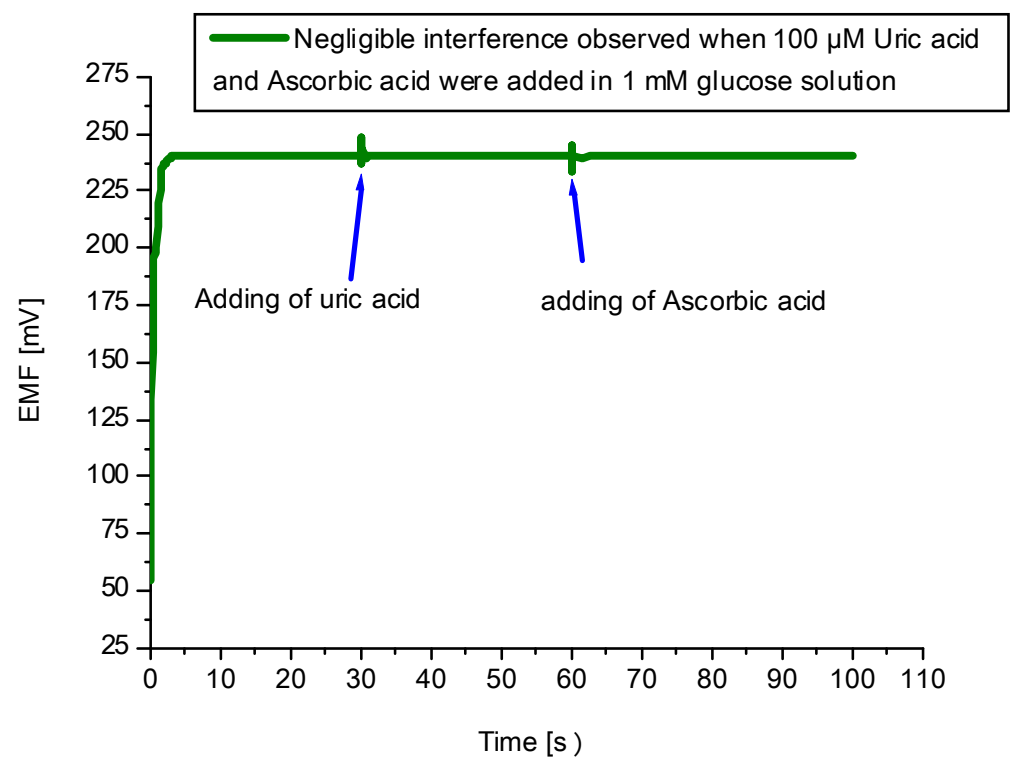




\section{References:}

[1] M. S. Wilson, "Electrochemical immuno-sensors for the simultaneous detection of two tumor markers," Analytical Chem., 77 (2005) 1496-1502.

[2] P. D’Orazio, “Biosensors in clinical chemistry,” Clin. Chim. Acta, 334 (2003) 41-69.

[3] C. Mousty, "Sensors and biosensors based on clay-modified electrodes-new trends," Appl. Clay Sci. 27 (2004) 159-177.

[4] H. Patel, X. Li, H.I. Karan, “Amperometric glucose sensors based on ferrocene containing polymeric electron transfer systems - a preliminary report," Biosens. Bioelectron," 18 (2003) 1073-1076.

[5] R. Nagata, S.A. Clark, K. Yokoyama, E. Tamiya, I. Karube, "Amperometric glucose biosensor manufactured by a printing technique," Anal. Chim. Acta 304 (1995) 157-164.

[6] G.W.J. Harwood, C.W. Pouton, "Amperometric enzyme biosensors for the analysis of drugs and metabolites," Adv. Drug Deliv. Rev. 18 (1996) 163-191.

[7] T. Saito, M. Watanabe, "Characterization of poly(vinylferrocene-co-2- hydroxyethyl methacrylate) for use as electron mediator in enzymatic glucose sensor," React. Funct. Polym. 37 (1998) 263-269.

[8] H. Liu, H. Li, T. Ying, K. Sun, Y. Qin, D. Qi, "Amperometric biosensor sensitive to glucose and lactose based on co-immobilization of ferrocene, glucose oxidase, galactosidase and mutarotase in-cyclodextrin polymer," Anal. Chim. Acta 358 (1998) 137-144.

[9] F. Ge, X.E. Zhang, Z.P. Zhang, X.M. Zhang, "Simultaneous determination of maltose and glucose using a screen-printed electrode system," Biosens. Bioelectron. 13 (1998) 333-339.

[10] X. Yang, L. Hua, H. Gong, S.N. Tan, "Covalent immobilization of an enzyme (glucose oxidase) onto a carbon sol-gel silicate composite surface as a biosensing platform," Anal. Chim. Acta 478 (2003) 67-75.

[11] S. Berchmans, R. Sathyajith, V. Yegnaraman, "Layer-by-layer assembly of 1,4diaminoanthraquinone and glucose oxidase," Mater. Chem. Phys. 77 (2002) 390-396.

[12] B. Alonso, P.G. Armada, J. Losada, I. Cuadrado, B. Gon' zalez, C.M. Casado, "Amperometric enzyme electrodes for aerobic and anaerobic glucose monitoring prepared by glucose oxidase immobilized in mixed ferrocene cobaltocenium dendrimers," Biosens. Bioelectron. 19 (2004) 1617-1625.

[13] J. Fei, K. Wu, F. Wang, S. Hu, "Glucose nanosensors based on redox polymer/ glucose oxidase modified carbon fiber nanoelectrodes," Talanta 65 (2005) 918-924.

[14] D. Pan, J. Chen, S. Yao, L. Nie, J. Xia, W. Tao, "Amperometric glucose biosensor based on immobilization of glucose oxidase in electropolymerized o-aminophenol film at coppermodified gold electrode," Sens. Actuator B 104 (2005) 68-74. 
[15] W.J. Guan, Y. Li, Y.Q. Chen, X.B. Zhang, G.Q. Hu, "Glucose biosensor based on multiwall carbon nanotubes and screen printed carbon electrodes," Biosens. Bioelectron. 21 (2005) $508-512$.

[16] M. Quinto, I. Losito, F. Palmisano, C.G. Zambonin, "Needle type glucose microbiosensor based on glucose oxidase immobilized in an overoxidised polypyrrole film (an in-vitro study)," J. Anal. Chem. (2000) 692-696.

[17] A. Guerrieri, G.E. De Benedetto, F. Palmisano, P.G. Zambonin," Electrosynthesized nonconducting polymers as permselective membrane in amperometric enzyme electrodes: a glucose biosensor based on a co-crosslinked glucose oxidase/overoxidized polypyrrole bilayer," Biosens. Bioelectron. 13 (1998) 103-112.

[18] B.M. Dixon, J.P. Lowry, R.D. O'Neill, "Characterization in vitro and in vivo of the oxygen dependence of an enzyme/polymer biosensor for monitoring brain glucose," J. Neurosci. Methods 119 (2002) 135-142.

[19] U. Harborn, B. Xie, R. Venkatesh, B. Danielsson, Evaluation of a miniaturized thermal biosensor for the determination of glucose in whole blood, Clin. Chim. Acta 267 (1997) 225237.

[20] S. Caras, J. Janata, Field effect transistors sensitive to penicillin, Anal. Chim. Acta 52 (1980) 1935-1937.

[21] F. Patolsky and C. M. Lieber, "Nanowires nanosensors," Mater. Today. 8(2005) 20-28.

[22] A. Errachid, N. Zine, J. Samitier, and J. Bausells, "FET-based chemical sensor systems fabricated with standard technologies," Electro analysis, 16 (2004) 1843-1851

[23] B. Eggins, "Chemical Sensors and Biosensors in Analytical Techniques in the Sciences," West Sussex: Wiley, 2002.

[24] M. J. Schoning and A. Poghossian, "Recent advances in biologically sensitive field-effect transistors (BioFETs)," Analyst, 127 (2002) 1137-1151.

[25] D. H. Wang, R. Kou, M. P. Gil, H. P. Jakobson, J. Tang, D. H. Yu, and Y. F. Lu, "Templated synthesis, characterization, and sensing application of macroscopic platinum nanowire network electrodes," J. Nanosci. Nanotechnol., 11(2005) 1904-1909.

[26] Y. K. Tseng, C. J. Huang, H. M. Cheng, I. N. Lin, K. S. Liu, I. C. Chen, "Characterization and Field-Emission Properties of Needle-like Zinc Oxide Nanowires Grown Vertically on Conductive Zinc Oxide Films”, Adv. Funct. Mater. 13 (2003) 811-814.

[27] Bao, J. M.; Zimmler, M. A.; Capasso, F.; Wang, X. W.; Ren, Z. F, "Broadband ZnO single-nanowire light-emitting diode", Nano Lett. 6 (2006) 1719-1722.

[28] Syed M. Usman Ali, O. Nur, M. Willander and B. Danielsson, "A fast and sensitive potentiometric glucose microsensor based on glucose oxidase coated $\mathrm{ZnO}$ nanowires grown on a thin silver wire", Sensor. Actuators B 145 (2010) 869-874. 
[29] Z. L. Wang, J. H. Song, "Piezoelectric Nanogenerators Based on Zinc Oxide Nanowire Arrays", Science, 312 (2006) 242-246.

[30] J. C. Johnson, K. P: Knutsen,H. Q. Yan, M. Law, Y. F. Zhang, P. D. Yang, "Ultrafast carrier dynamics in single $\mathrm{ZnO}$ nanowire and nanoribbon lasers", Nano Lett. 4 (2004) 197204.

[31] J. X. Wang, X. W. Sun, H. Huang, Y. C. Lee, O. K. Tan, M. B. Yu, G. Q. Lo, “A two-step hydrothermally grown $\mathrm{ZnO}$ microtube array for $\mathrm{CO}$ gas sensing", Appl. Phys. A 88 (2007) 611-615.

[32] T. J. Hsueh, S. J. Chang, C. L. Hsu, Y. R. Lin and I. C. Chen, "ZnO nanotube ethanol gas sensors", J. Electrochem. Soc., 155(2009) K152-K155.

[33] T. Kong, Y. Chen, Y. P. Ye, K. Zhang, Z. X. Wang, X. P. Wang, “An amperometric glucose biosensor based on the immobilization of glucose oxidase on the $\mathrm{ZnO}$ nanotubes", Sensor. Actuators B 138 (2009) 344-350

[34] A. Fulati, Syed M. Usman Ali, M. H. Asif, N. H. Alvi, M. Willander, C. Brännmark, P. Strålfors , S. I. Börjesson , F. Elinder, B. Danielsson," An intracellular glucose biosensor based on nanoflakes ZnO”, Sensors. Actuators B 150 (2010) 673-680.

[35] A. Wei, X.W. Sun, J.X. Wang, Y. Lei, X.P. Cai, C.M. Li, Z.L. Dong, W. Huang, Enzymatic glucose biosensor based on $\mathrm{ZnO}$ nanorod array grown by hydrothermal decomposition, Appl. Phys. Lett. 89 (2006) 123902-123904.

[36] S.M. Usman Ali, O. Nur, M. Willander, B. Danielsson, Glucose detection with a commercial MOSFET using a $\mathrm{ZnO}$ nanowires extended gate, IEEE Trans. Nanotechnol. 8 (2009) 678-683.

[37] M. H. Asif, S.M. Usman Ali, O. Nur, M. Willander, C. Brännmark,P. Strålfors, U. H. Englund, F. Elinder, B. Danielsson, "Functionalised ZnO-nanorod-based selective electrochemical sensor for intracellular glucose”, Biosens. Bioelectron. 25 (2010) 2205-2011

[38] S. M. Usman Ali, M.H. Asif , A. Fulati , O. Nur, M. Willander, C. Brännmark, P. Strålfors, U. H. Englund, F. Elinder and B. Danielsson, "Intracellular K+ determination with a potentiometric microelectrode based on $\mathrm{ZnO}$ nanowires", IEEE Tnano. D10.1109/TNANO.2010.2089696

[39] L. E. Greene, M. Law, J. Goldberger, F. Kim, J. C. Johnson, Y. Zhang, R. J. Saykally, P. Yang, "Low-Temperature Wafer-Scale Production of ZnO Nanowire Arrays", Angew. Chem. Int. Ed. 42 (2003) 3031-3034

[40] L. Vayssieres, k. Keis, S. E. Lindquist, A. Hagfeldt, "Purpose-Built Anisotropic Metal Oxide Material: 3D Highly Oriented Microrod Array of ZnO” J. Phys. Chem. B 105 (2001) 3350-352 
[41] Q. Li, V Kumar, Y. Li, H. Zhang, T. J. Marks, R.P.H. Chang, "Fabrication of ZnO Nanorods and Nanotubes in Aqueous Solutions", Chem. Mater. 17 (2005) 1001-1006.

[42] J. Elias, R. Tena-Zaera, G. Y. S. Wang, C. Levy-Clement, "Conversion of ZnO Nanowires into Nanotubes with Tailored Dimensions" Chem. Mater. 20 (2008) 6633-6637.

[43] Z. Fan, D. J. Harrison, "Permeability of glucose and other neutral species through recast perfluorosulfonated ionomer films", Anal. Chem. 64 (1992) 1304-1311.

[44] G. Fortier, M. Vaillancourt, D. Belanger, "Evaluation of nafion as media for glucose oxidase immobilization for the development of an amperometric glucose biosensor", Electro analysis. 4 (1992) 275-283.

[45] B. H. Chu, B. S. Kang, S. C. Hung, K. H. Chen,F. Ren, A. Sciullo, B. P. Gila and S. J.

Pearton, "Aluminum gallium nitride $(\mathrm{GaN}) / \mathrm{GaN}$ high electron mobility transistor-based sensors for glucose detection in exhaled breath condensate", J. Diabes Sci. \& tech. 4(2010) $171-179$

[46] B. S. Kang, H. T. Wang, F. Ren, S. J. Pearton, T. E. Morey, D. M. Dennis, J. W. Johnsons, P. Raja gopal, J. C. Roberts, E. L. Piner, and K. J. Linthicum, "Enzymatic glucose detection using $\mathrm{ZnO}$ nanorods on the gate region of $\mathrm{AlGaN} / \mathrm{GaN}$ high electron mobility transistors", Appl. Phys. Lett. 91(2007) 252103-252106. 